\title{
Sulforaphane promotes ER stress, autophagy, and cell death: implications for cataract surgery
}

\author{
Hanruo Liu ${ }^{1,2} \cdot$ Andrew JO Smith ${ }^{2} \cdot$ Simon SR Ball $^{2}$ - Yongping Bao ${ }^{3} \cdot$ \\ Richard P Bowater $^{2} \cdot$ Ningli Wang $^{1} \cdot$ I. Michael Wormstone ${ }^{2}$
}

Received: 7 October 2016/Revised: 17 December 2016/Accepted: 20 December 2016/Published online: 12 January 2017

(C) The Author(s) 2017. This article is published with open access at Springerlink.com

\begin{abstract}
Posterior capsule opacification (PCO) commonly develops following cataract surgery and is a wound-healing response that can ultimately lead to secondary visual loss. Improved management of this problem is required. The isothiocyanate, sulforaphane (SFN), is reported to exert cytoprotective and cytotoxic actions, and the latter may be exploited to treat/ prevent PCO. SFN concentrations of $10 \mu \mathrm{M}$ and above significantly impaired wound-healing in a human lens capsular bag model. A similar pattern of response was also seen with a human lens cell line, FHL124. SFN treatment promoted increased expression of endoplasmic reticulum (ER) stress genes, which also corresponded with protein expression. Evidence of autophagy was observed in response to SFN as determined by increased microtubule-associated protein $1 \mathrm{~A} /$ 1B-light chain 3 (LC3)-II levels and detection of autophagic vesicles. This response was disrupted by established autophagy inhibitors chloroquine and 3-MA. SFN was found to promote MAPK signaling, and inhibition of ERK activation using U0126 prevented SFN-induced LC3-II elevation and vesicle formation. SFN also significantly increased levels of reactive oxygen species. Taken together, our findings suggest that SFN is capable of reducing lens cell growth and viability and thus could serve as a putative therapeutic agent for PCO.
\end{abstract}

I. Michael Wormstone

i.m.wormstone@uea.ac.uk

1 Beijing Institute of Ophthalmology, Beijing Tongren Hospital, Capital Medical University, Beijing, China

2 School of Biological Sciences, Norwich Research Park, University of East Anglia, Norwich NR4 7TJ, UK

3 Norwich Medical School, University of East Anglia, Norwich NR4 7TJ, UK

\section{Key message}

- SFN reduces lens epithelial cell growth, migration, and viability.

- SFN can promote ER stress and autophagy in lens cells.

- SFN promotes MAPK signaling, and inhibition of MEK can suppress SFN-induced autophagy.

- ER stress and autophagy in lens cells are likely promoted by ROS production.

- SFN may help prevent posterior capsule opacification after cataract surgery.

Keywords Sulforaphane $\cdot$ ER stress $\cdot$ Autophagy flux $\cdot$ Lens . Posterior capsule opacification

\section{Introduction}

Cataract renders millions of people blind throughout the world. Despite recent advances in putative cataract treatments, the only currently accepted means of resolving the problem is through surgical intervention $[1,2]$. Cataract removal is the most common surgical procedure in the world and is a huge drain on healthcare providers $[3,4]$. Posterior capsule opacification (PCO) is the most common complication of cataract surgery and likely the most common cause of nonrefractive decreased postoperative vision $[5,6]$. PCO occurs in a significant proportion of cataract surgery patients within 5 years postoperatively, depending on age, geographic location, and the type of intraocular lens (IOL) placed during cataract surgery $[2,7]$. PCO reflects the wound-healing process of the lens epithelial cells (LECs) that remain in the capsular bag after cataract surgery. Residual LECs within the capsular bag rapidly grow and proliferate across the posterior lens capsule, which can encroach upon the visual axis and 
cause a secondary reduction in vision quality [8]. Treatment of PCO is usually straightforward and effective, using the neodymium:YAG (Nd:YAG) laser to cut an opening in the posterior lens capsule, thus clearing the visual axis and restoring vision [2]. However, disruption of the posterior capsule due to complications of cataract surgery results in a relative increase in the occurrence of complications such as an elevation in intraocular pressure, retinal cystoid macular edema, glaucoma, intraocular lens damage, iritis, endophthalmitis, and retinal detachment [9]. Nd:YAG treatment is the second most common corrective surgery, which provides further cost to healthcare providers not to mention the reduced quality of life experienced by the patient as PCO develops. Thus, PCO is an important problem, and thus, improved management of this condition is required. A number of strategies have been proposed but are yet to reach the clinic. These include mechanical approaches, which strive to remove all LECs during surgery or by altering shape and materials of the IOL designs $[10,11]$. Different pharmaceutical methods to prevent $\mathrm{PCO}$ by removing or destroying residual LECs have also been proposed that can either arrest growth, prevent matrix contraction, or destroy the entire lens cell population [12-15].

In the present study, we investigated sulforaphane [1isothiocyanato-4-(methylsulfinyl)-butane, sulforaphane $(\mathrm{SFN})]$ in the prevention of PCO. SFN is an organic isothiocyanate that is derived from glucosinolates found in cruciferous vegetables [16]. SFN is an intriguing molecule as it is reported to play a role in both cytoprotection and cytotoxicity. These contrasting outcomes are governed by concentration, such that a threshold is eventually reached that is associated with reduced cell viability and death. In the lens, we have previously shown that low micromolar concentrations of SFN do not reduce cell viability or promote cell death [17]. At these lower concentrations, Nrf2 signaling is activated, which leads to increased expression of antioxidant response proteins and thus better prepares cells to manage oxidative stress. Similar responses have also been observed in other cells and tissue [16]. SFN was also found to prevent oxidative stress-induced opacity of cultured whole lenses [17]. With respect to cytotoxic actions of SFN, it has been reported to inhibit tumor growth in many in vivo models by inducing cell cycle arrest and instigating apoptosis [18, 19]. Also, SFN has been proposed to reduce proliferation and promote cell death via ROS generation [20, 21].

In the present study, we aimed to assess whether SFN could reduce cell growth and promote cell death using a human tissue culture model and a human lens cell line, using them as a tool to identify mechanisms that drive these different cellular outcomes. In particular, we elected to investigate the potential involvement of endoplasmic reticulum (ER) stress pathways [22, 23] and autophagy [24, 25]. ER stress is reported to be enhanced by SFN [26, 27]. Similarly, SFN can also initiate autophagy in several cell types [28], which in addition to its housekeeping role can also contribute to cell death in certain circumstances [29]. Our investigation revealed a cytotoxic action of SFN in our human lens capsular bag model, which is an excellent predictive tool for clinical outcomes. Using a human lens cell line, we also identified that SFN can promote ER stress and autophagy in human lens cells. In the case of autophagy, SFN-mediated MAPK signaling appears to play an important role.

\section{Materials and methods}

\section{Human lens capsular bag preparation}

Simulated cataract operations were performed to create capsular bags from human donor lenses [30] that were obtained with informed consent and used in accordance with the tenets of the Declaration of Helsinki. Approval for the study and experimental protocols $(04 / \mathrm{Q} 0102 / 57)$ was granted by a national research ethics committee under the Health Research Authority (UK). Using an insulin needle, the anterior capsule was breached approximately $3 \mathrm{~mm}$ from the equator, and an incision was made from that point to the center of the capsule. By tugging the flap, created by this incision, with surgical forceps, a continuous curvilinear capsulorhexis was created, such that a disc of anterior capsule was removed, leaving an opening approximately $5 \mathrm{~mm}$ in diameter. The resultant window enabled the lens fiber mass to be removed by hydroexpression. Residual fibers were removed by joint irrigation with Hartmann's solution and aspiration. The resultant capsular bag was then dissected free of the zonules and secured on a sterile $35-\mathrm{mm}$ polymethylmethacrylate (PMMA) Petri dish. Eight entomological pins (Anglian Lepidopterist Supplies, Hindolveston, Norfolk, UK) were inserted through the edge of the capsule to retain its circular shape. Capsular bags were maintained in $1.5 \mathrm{~mL}$ Eagle's minimum essential medium (EMEM) (Sigma-Aldrich, Poole, UK) and incubated at $35{ }^{\circ} \mathrm{C}$ in a $5 \% \mathrm{CO}_{2}$ atmosphere. Preparations were exposed to $0,1,10$, or $100 \mu \mathrm{M} \mathrm{SFN}$ for the first $24 \mathrm{~h}$ of culture and then maintained in unsupplemented EMEM for the remaining experimental period (end point at 30 days). Ongoing observations were made using a Nikon phase-contrast microscope (Nikon, Tokyo, Japan).

\section{FHL124 human lens cell line}

FHL124 is a nonvirally transformed cell line generated from human capsule-epithelial explants, showing a $99.5 \%$ homology (in transcript profile) with the native lens epithelium [31]. FHL124 cells were routinely cultured at $35^{\circ} \mathrm{C}$ in a humidified atmosphere of $95 \%$ air and $5 \% \mathrm{CO}_{2}$, in EMEM supplemented with 5\% fetal calf serum (FCS) (Gibco, Paisley, UK) and $50 \mu \mathrm{g} / \mathrm{mL}$ gentamicin (Sigma-Aldrich). FHL124 cells were 
seeded on the following: 35 -mm tissue culture dishes $(30,000$ / dish for Western blot, qRT-PCR, TEM, and scratch migration assay), coverslips $(10,000)$ for immunocytochemistry, and 96well plates (5000/well for MTS (3-(4,5-dimethylthiazol-2-yl)5-(3-carboxymethoxyphenyl)-2-(4-sulfophenyl)-2H-tetrazolium) assay and ROS detection assay (Promega, Madison, WI) and lactate dehydrogenase (LDH) assay (Roche).

\section{Cell viability}

A cell proliferation assay (CellTiter 96 AQueous; Promega) was used in accordance with the manufacturer's instructions to assess FHL124 cell viability. This assay is a colorimetric method for determining the number of viable cells in proliferation. The assay is based on the cellular conversion of a tetrazolium salt (MTS) into a formazan product. The resultant absorbance is directly proportional to the number of viable cells in culture. Absorbance was measured at $490 \mathrm{~nm}$ with a spectrophotometric plate reader (FLUOstar Omega plate reader; BMG Labtech).

\section{Cell death assay}

A nonradioactive cytotoxicity assay (CytoTox 96R; Roche, Welwyn Garden City, UK) was used to measure the release of LDH from cultured human lens cells. The procedure followed the manufacturer's protocol. The plate was read at $490 \mathrm{~nm}$ with a FLUOstar Omega plate reader (BMG Labtech).

\section{Scratch wound assay}

FHL124 cells in each well were allowed to grow to 95\% confluence. Cells were then placed in unsupplemented EMEM for a 24-h period. A scratch was made through the sheet of cells using a plastic pipette tip. Photomicrographs were taken immediately after the scratch was made and after $24 \mathrm{~h}$ of incubation in experimental conditions. Image $1.45 \mathrm{~s}$ analysis software (available in the public domain at http://rsbweb.nih.gov/ij/) was then used to quantify the initial scratch area and the final area of the scratch.

\section{TaqMan qRT-PCR}

qRT-PCR reactions were performed using an ABI prism 7700 Sequence Detection System (Applied Biosystems, Warrington, UK) under the following conditions: $50{ }^{\circ} \mathrm{C}$ for $2 \mathrm{~min}, 95^{\circ} \mathrm{C}$ for $10 \mathrm{~min}$, and then 40 cycles, each consisting of $15 \mathrm{~s}$ at $95^{\circ} \mathrm{C}$ and $1 \mathrm{~min}$ at $60^{\circ} \mathrm{C}$. Each reaction was performed in $25 \mu \mathrm{L}$ and contained reverse transcribed RNA, primers, and probes (sequences for primers and probes are given in Table 1) and TaqMan PCR master mix (Applied Biosystems). Primers and probes were bought as predesigned TaqMan probe and primer sets provided by Applied Biosystems. The threshold cycle $(\mathrm{Ct})$ values, defined as the point at which the fluorescent
Table 1 Predesigned TaqMan probe/primer sets for genes of interest

\begin{tabular}{llll}
\hline Gene name & Protein encoded & Ref seq & $\begin{array}{l}\text { TaqMan primer/ } \\
\text { probe set }\end{array}$ \\
\hline AFT6 & AFT6 & NM_007348 & Hs00232586_m1 \\
ERN1 & IRE1 & NM_001433 & Hs00176385_m1 \\
EIF2AK3 & EIF2 $\alpha$ & NM_003836.3 & Hs00178128_m1 \\
HSPA5 & BiP & NM_004836.3 & Hs99999174_m1
\end{tabular}

signal is recorded as statistically above background, were obtained using the 7500 Fast system software 2.0.5 (Applied Biosystems).

\section{Immunoblotting}

Cell lysates from FHL124 cells were prepared using Daub's lysis buffer supplemented with $1 \mathrm{mM}$ phenylmethylsulfonyl fluoride (PMSF) and $10 \mu \mathrm{g} / \mathrm{mL}$ aprotinin for $20 \mathrm{~min}$ on ice and centrifuged at $16,060 \times \mathrm{g}$ for $10 \mathrm{~min}$. The protein content was determined by the BCA assay (Bio-Rad, Hemel Hempstead, UK) so that equal amounts of protein per sample were loaded onto $8 \%$ SDS-polyacrylamide gels and transferred to PVDF membrane using a semidry transfer cell. The membrane was blocked with PBS containing 5\% nonfat dry milk and $0.1 \%$ Tween-20, hybridized with primary antibody (anti-LC3, (Sigma-Aldrich, Poole, Dorset); anti-ERK, antiJNK, anti-p38, anti- $\beta$-actin (Cell Signaling Technology, Beverly, MA, USA), anti-EIF-2 $\alpha$, anti-BiP/GRP78 (BioSource International, Rockville, MD); anti-IRE1, antiATF6 (Abcam, Cambridge, UK)) followed by incubation with secondary antibody (Amersham Biosciences, Bucks, UK). Proteins were detected using the ECL plus blotting analysis system (Amersham Biosciences).

\section{Transmission electron microscopy}

Cultured FHL124 were treated with $100 \mu \mathrm{M}$ SFN for $24 \mathrm{~h}$ $(n=4)$ to fixation with $3 \%$ gluteraldehyde in $0.1 \mathrm{M}$ phosphate buffer (pH 7.2) and 2\% paraformaldehyde (PFA) for $24 \mathrm{~h}$. Following fixation, samples were post-fixed in $1 \% \mathrm{OsO}_{4}$ in the same buffer for $30 \mathrm{~min}$. Appropriate areas for thin sectioning were cut at $70 \mathrm{~nm}$ and stained with saturated $2 \%$ uranyl acetate and $2 \%$ lead citrate before examination on a transmission electron microscope (Libra 120, Carl Zeiss) at $120 \mathrm{kV}$.

\section{Immunofluorescence}

Cells were maintained in unsupplemented EMEM for $24 \mathrm{~h}$ before being placed in experimental conditions for selected periods. Cells were fixed with $4 \%$ formaldehyde in PBS for $30 \mathrm{~min}$ and permeabilized with PBS containing $0.5 \%$ Triton $\mathrm{X}-100$ for $30 \mathrm{~min}$. Preparations were washed three times for 
$5 \mathrm{~min}$ in PBS containing $0.02 \% \mathrm{w} / \mathrm{v} \mathrm{BSA}$ and $0.05 \% \mathrm{v} / \mathrm{v}$ IGEPAL. Nonspecific sites were blocked with normal goat or donkey serum (1:50 in 1\% $w / v$ BSA in PBS). Following removal of the blocking buffer, rabbit polyclonal primary antibody against microtubule-associated protein 1A/1B-light chain 3 (LC3) (Sigma-Aldrich, Poole, Dorset) diluted 1:200 was applied overnight at $4{ }^{\circ} \mathrm{C}$. Cells were subsequently washed with PBS and placed in ALEXA-488 conjugated secondary antibody (1:250; Invitrogen) for $1 \mathrm{~h}$ at room temperature. The stained preparations were again washed extensively and mounted on microscope slides with Hydromount mounting medium (National Diagnostics, Hull, UK). Images were viewed using fluorescence microscopy (Axioplan 2; Zeiss), and applicable images were quantified using ImageJ1.45s analysis software (available in the public domain at http://rsbweb.nih.gov/ij/).

\section{ROS detection assay}

ROS levels were measured using a cellular reactive oxygen species detection assay (Abcam, UK) that uses the cell permeant reagent $2^{\prime}, 7^{\prime}$-dichlorofluorescin diacetate (DCFDA) to measure hydroxyl, peroxyl, and other ROS activities. This was in accordance with manufacturer instructions. The cells were washed with buffer before being stained with $20 \mu \mathrm{M}$ DCFDA for $45 \mathrm{~min}$ at $37^{\circ} \mathrm{C}$, and then washed with buffer again before addition of EMEM and test compounds. The fluorescence (excitation/emission was 485/ $535 \mathrm{~nm}$, respectively) was then measured following a 2-h incubation.

\section{Statistical analysis}

A Student's $t$ test analysis was performed using Excel software (Microsoft, Redmond, WA) to determine any statistical difference between two groups. One-way ANOVA with Tukey's post hoc analysis was used to assess multiple groups when all or many pairwise comparisons were of interest. Oneway ANOVA with Dunnett's post hoc analysis was used to assess all groups compared against the control group. A 95\% confidence interval was used to assess significance.

\section{Results}

\section{SFN can reduce lens cell coverage and promote cell death}

Capsular bags maintained in standard serum-free culture conditions demonstrated progressive cell growth across denuded regions of the anterior capsule, the outer anterior capsule, and, importantly, the previously cell-free posterior capsule. At day 8 , cells could be clearly seen on the central posterior capsule. The level of growth in capsular bag preparations treated with $1 \mu \mathrm{M}$ SFN for the first $24-\mathrm{h}$ period of culture was similar to control preparations (Fig. 1a, b). Cells were also observed on the central posterior capsule with $10 \mu \mathrm{M}$ SFN, but growth was retarded (Fig. 1a, b). Limited coverage of the central posterior capsule was seen with $100 \mu \mathrm{M}$ SFN, and indeed, the cells on the anterior capsule appeared distressed at this time point (Fig. 1a, b). Following 30 days of culture (end point), control capsular bags exhibited complete coverage of the posterior capsule (Fig. 1c, d). Exposure to $1 \mu \mathrm{M}$ SFN for the first $24 \mathrm{~h}$ of culture had negligible effect on cell coverage by day 30 (Fig. 1c, d). Capsular bags exposed to $10 \mu \mathrm{M} \mathrm{SFN}$ for $24 \mathrm{~h}$ demonstrated a marked reduction in cells growing on the posterior capsule, and 24-h treatment with $100 \mu \mathrm{M}$ SFN leads to widespread cell death and completely inhibited coverage of the posterior capsule (Fig. 1c, d).

Previous work has shown that SFN can reduce cell viability and induce death (by apoptosis) of FHL124 cells [17]; this was determined using the ApoTox-Glo Triplex assay (Promega). In the current study, we verified this response using different biochemical assays. The MTS assay was used to assess cell viability, and it was found that SFN reduced cell viability in a concentration-dependent manner, such that significant differences from control were seen with treatments at $10 \mu \mathrm{M}$ and above (Fig. 1e). Cell damage/death was observed using the LDH assay, and in this case, significant increases in LDH levels were detected with 10-, 30-, and 100- $\mathrm{MM}$ treatments (Fig.1f).

We further assessed the impact of SFN on wound-healing of FHL124 cells using the scratch assay method. Following wound formation, control and $1 \mu \mathrm{M}$ SFN-treated cells were seen to close the denuded region at similar rates. However, significant inhibition of wound closure was observed with 10-, 30-, and 100- $\mathrm{MM}$ SFN treatments (Fig. 1g).

The findings with the cell line demonstrate that this system is a relevant model to study SFN in relation to PCO and lens cell behavior. We therefore employed this biological tool to further investigate the mechanisms governed by SFN that could contribute to abrogation in the wound-healing response.

\section{Promotion of ER stress pathways by SFN}

In order to investigate the putative involvement of ER stress in SFN-mediated events, real-time PCR and Western blot analysis were employed. FHL124 cells were treated with 10, 30, and $100 \mu \mathrm{M}$ SFN for $24 \mathrm{~h}$. Real-time PCR revealed increases in all four ER stress gene products tested in FHL124 cells after exposure to SFN for $24 \mathrm{~h}$ (Fig. 2). The level of the inositolrequiring enzyme 1 (IRE1) gene (ERN1) in lens cells was significantly increased within $24 \mathrm{~h}$ of exposure to $30 \mu \mathrm{M}$ SFN (Fig. 2d). All genes were significantly elevated at $100 \mu \mathrm{M} \mathrm{SFN}$ (Fig. 2a-d). At the protein level, binding immunoglobulin protein $(\mathrm{BiP})$, activating transcription factor 6 (ATF6), eukaryotic translation initiation factor $2 \alpha$ (EIF2 $\alpha$ ), and IRE1 were significantly upregulated in response to a 

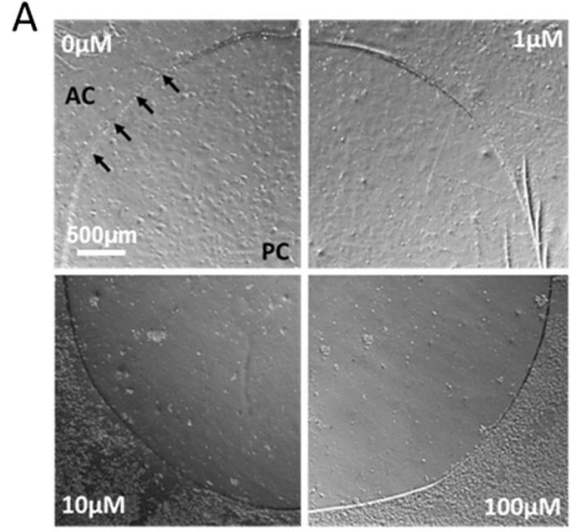

B

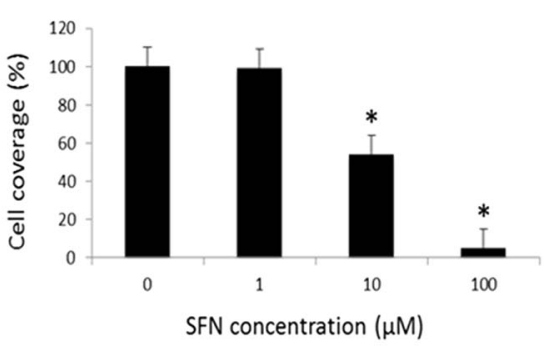

C

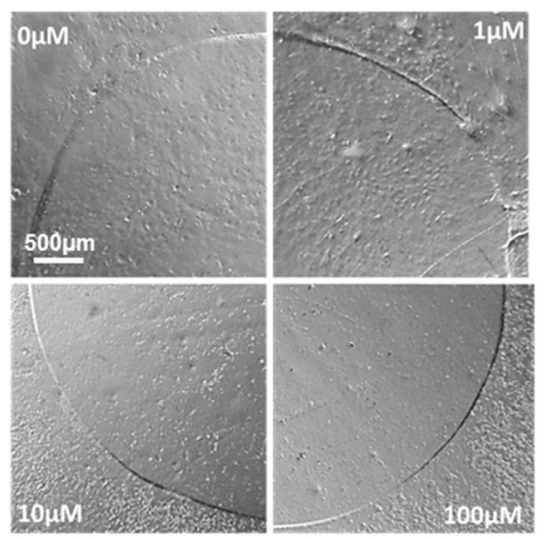

D

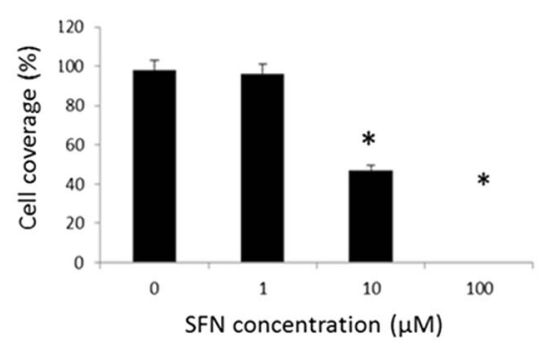

$\mathrm{E}$

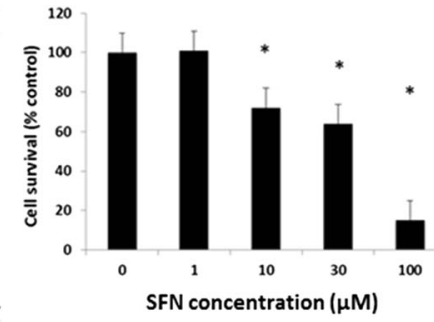

F

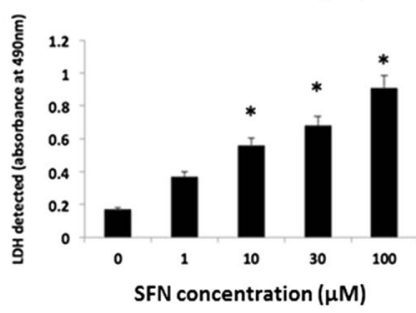

G

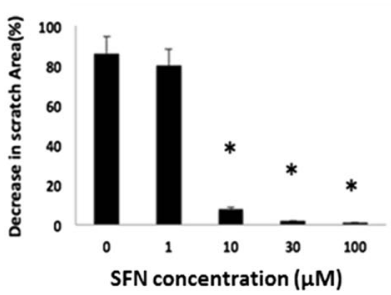

Fig. 1 The effect of SFN on cell survival and growth of human lens cells. Modified dark-field images of four human capsular bag quarters showing the posterior capsule $(P C)$, capsulorhexis (arrowed), and outer anterior capsule $(A C)$ captured after a 8 and c 30 days. Cell coverage on the posterior capsule was quantified from dark-field images at $\mathbf{b} 8$ and $\mathbf{d}$ 30 days. Data are presented as mean $\pm \operatorname{SEM}(n=4)$. Asterisk indicates a significant difference between treated and control groups. The effects of
SFN exposure to FHL124 cells over a 24-h period on e cell viability, $\mathbf{f}$ cell death, and $\mathbf{g}$ migration assessed using the MTS, LDH, and scratch wound assays, respectively. The data are presented as mean \pm SEM of four independent experiments. Asterisk represents a significant difference between untreated control and treatment groups $(p \leq 0.05$; ANOVA with Dunnett's post hoc test)
A

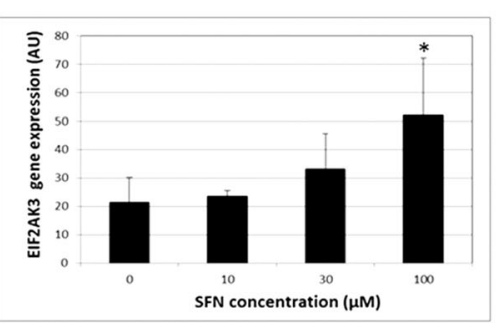

B

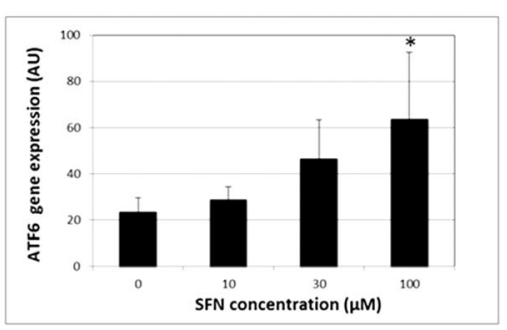

C

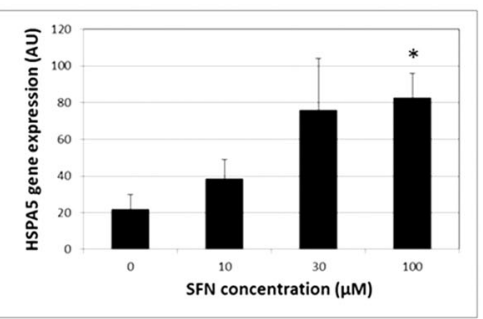

D

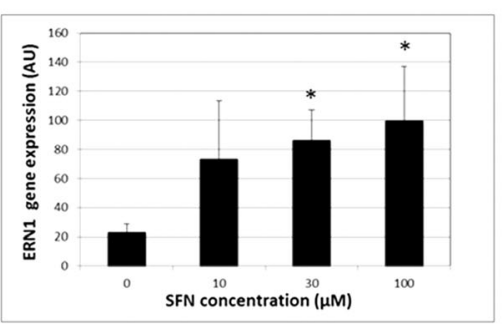

$\mathrm{E}$

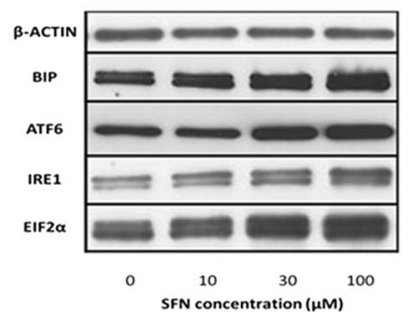

$\mathrm{F}$

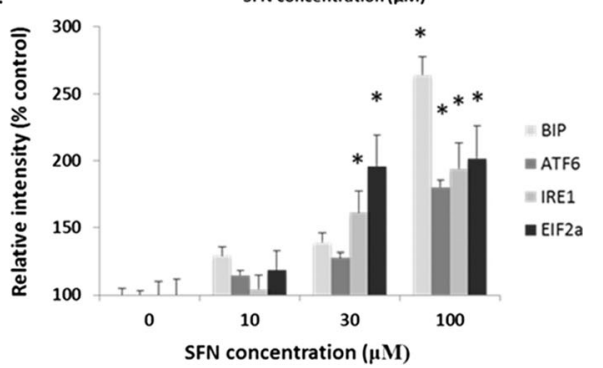

Fig. 2 SFN can induce ER stress in FHL124 human lens epithelial cells. Gene expression of a EIF2AK3, b ATF6, c HSPA5, and d ERN1 following 24-h exposure to SFN concentrations, detected by real-time PCR. Values were normalized to $18 \mathrm{~S}$ gene expression. The data represent mean $\pm \operatorname{SEM}(n=4)$. Asterisk represents a significant difference between untreated control and treated groups $(p \leq 0.05$; ANOVA with Dunnett's post hoc test). Detection of ER stress proteins in response to SFN was determined using Western blot methods. e
Representative blots showing BiP, ATF6, IRE1, EIF2 $\alpha$, and $\beta$-actin levels within FHL124 cells; product bands were observed at $\sim 78,75$, 107,36 , and $45 \mathrm{kDa}$, respectively. f Quantitative data derived from band intensities; the protein band intensities for BiP, ATF6, IRE1, and EIF $2 \alpha$ were normalized to $\beta$-actin. Data are presented as mean \pm SEM $(n=4)$. Asterisk indicates a significant difference between treated and nontreated control groups $(p \leq 0.05$; ANOVA with Dunnett's post hoc test) 
24-h 100- $\mu \mathrm{M}$ SFN treatment. When cells were exposed to $30 \mu \mathrm{M}$ SFN, there were significant increases in IRE1 and EIF $2 \alpha$ expression (Fig. 2e, f).

\section{SFN can promote autophagy in lens cells}

To examine whether SFN could induce autophagy in LEC cells, FHL124 cells were treated with 1,10 , and $100 \mu \mathrm{M}$ SFN for $24 \mathrm{~h}$. The level of LC3, a well-known protein associated with autophagosome membranes, was analyzed by Western blot. While expression of LC3-I was consistent in all treatment groups, the level of LC3-II in cells treated with SFN was significantly increased compared to control cells without SFN treatment (Fig. 3a, b). To provide further evidence of autophagy in response to SFN, we examined cells using transmission electron microscopy (Fig. 3c) and immunofluorescence (Fig. 3d, e). Using these methods, we could observe increased numbers of autophagosomes in cells treated with 10 and $100 \mu \mathrm{M}$ SFN.

The increase of LC3-II could result from several events, including an interruption in autophagosome-lysosome fusion, inhibiting lysosome-mediated proteolysis or raising the lysosomal $\mathrm{pH}$ [29]. To further clarify whether the increased level of LC3-II by SFN treatment was caused by interrupting the autophagosome-lysosome
Fig. 4 Chloroquine and 3-MA disrupt SFN-induced autophagy responses in FHL124 human lens epithelial cells. LC3 levels detected using Western blot methods and autophagic vesicle formation in response to $100 \mu \mathrm{M}$ SFN treatment in the presence and absence of $50 \mu \mathrm{M}$ chloroquine $(\mathbf{a}-\mathbf{d})$ and $500 \mu \mathrm{M} 3-\mathrm{MA}(\mathbf{e}-\mathbf{h})$. Western blots detected products for LC3-I and LC3-II at $\sim 18$ and $16 \mathrm{kDa}$; a band corresponding to $\beta$-actin was detected at $45 \mathrm{kDa}$. Data are presented as mean $\pm \operatorname{SEM}(n=3)$. Asterisk indicates a significant difference from all other groups ( $p \leq 0.05$; ANOVA with Tukey's post hoc test)

fusion or not, we treated FHL124 cells with $100 \mu \mathrm{M}$ SFN in the presence of $50 \mu \mathrm{M}$ chloroquine (CQ) which is a classic lysosomal inhibitor, for $6 \mathrm{~h}$ (Fig. 4a-d). Using this approach, we observed a significant increase in LC3II levels relative to control when SFN and CQ were added alone. Application of SFN and CQ together led to a further significant increase. These results were also mirrored using immunofluorescence, which demonstrated significant changes in autophagic vesicle numbers with SFN and CQ, which were further elevated with co-treatment. To further assess the hypothesis that SFN can induce autophagy in FHL124 cells, 3-methyladenine (3-MA) was utilized as an early-stage autophagy inhibitor. Treatment with $100 \mu \mathrm{M}$ SFN induced significant increases in LC3-II levels and autophagosome numbers. These responses were significantly suppressed by co-treatment with $500 \mu \mathrm{M}$ 3-MA (Fig. 4e-h).

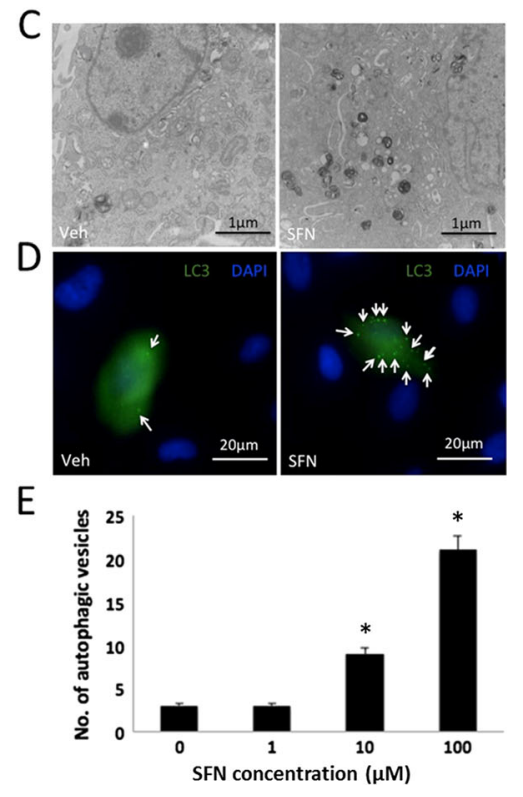

of autophagic vesicles can be clearly seen with SFN treatment. Fluorescence micrographs showing LC3 distribution in association with autophagic vesicles in control and $100 \mu \mathrm{M}$ SFN-treated cells (c, d); representative images (c) and quantitative data pooled from three separate experiments (d) are presented. Data are presented as mean \pm SEM. Asterisk indicates a significant difference between the treated group and untreated controls $(p \leq 0.05$; ANOVA with Dunnett's post hoc test) 
A

\section{LC3- I}

LC3- II

$\beta$-actin

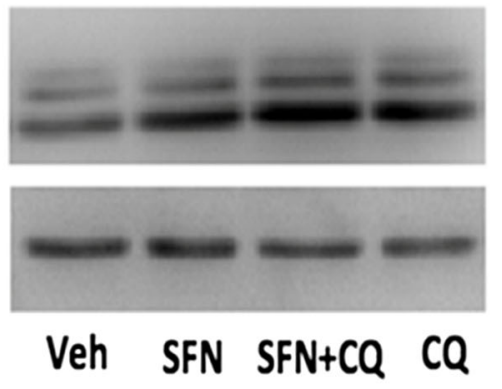

B

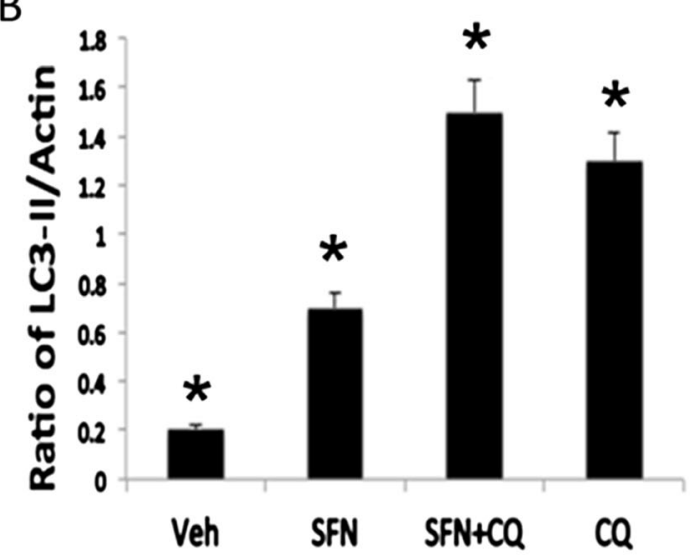

C

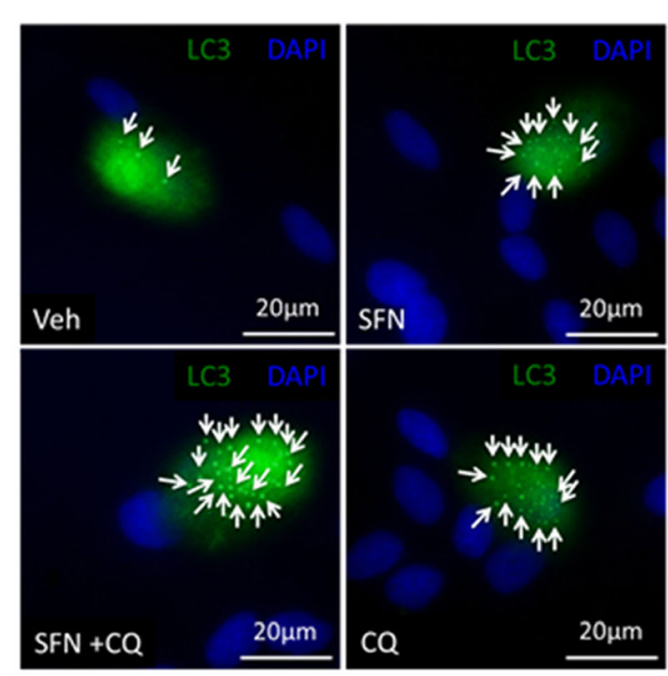

D

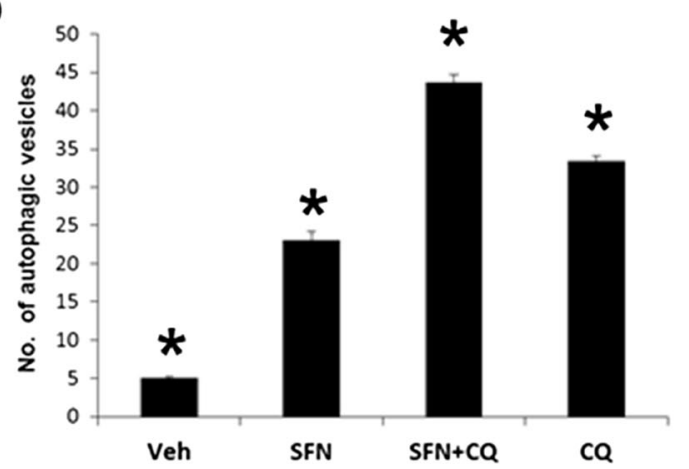

E

LC3- I

LC3-II

$\beta$-actin

Veh SFN SFN+3-MA 3-MA

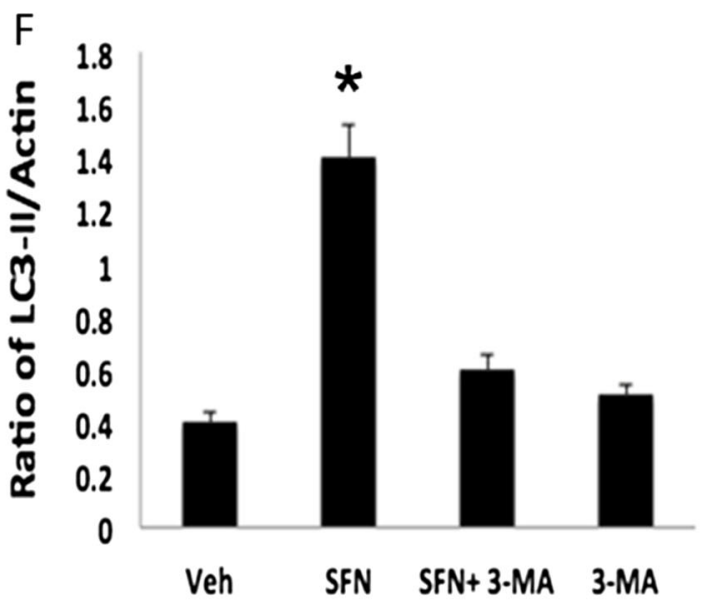

G

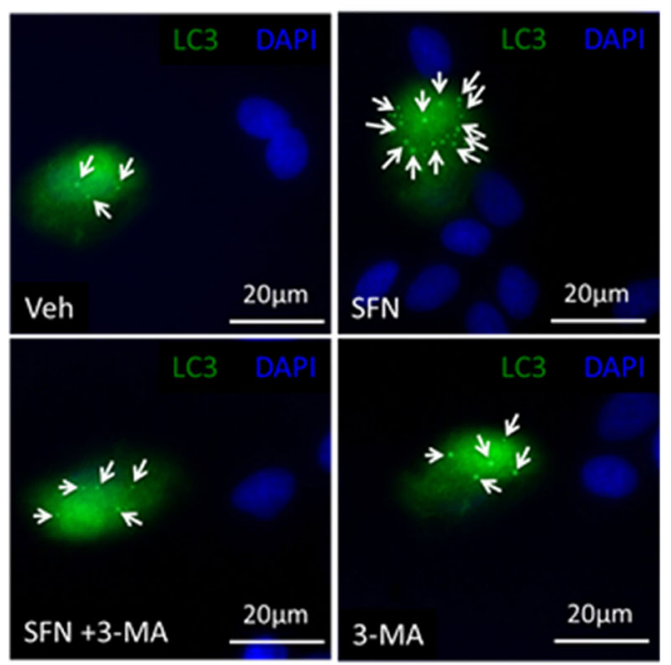

$\mathrm{H}$

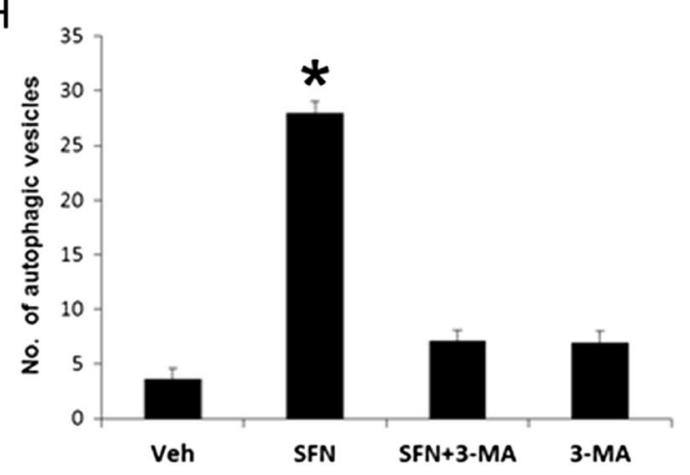


Fig. 5 MAPK signaling involvement in SFN-induced autophagy in FHL124 human lens epithelial cells. The effects of $100 \mu \mathrm{M}$ SFN on $\mathrm{p} 38$, JNK, and ERK phosphorylation in conjunction with LC3-II levels detected by Western blot methods (a, b); representative blots showing products at $\sim 44 / 42 \mathrm{kDa}$ (phospho and total ERK1/2), $46 \mathrm{kDa}$ (phospho and total JNK1), $38 \mathrm{kDa}$ (phospho and total p38), and $45 \mathrm{kDa}$ ( $\beta$-actin) (a) and pooled quantitative data (b) are presented. Data are presented as mean $\pm \operatorname{SEM}(n=4)$. Asterisk indicates a significant difference between treated and nontreated control groups ( $p \leq 0.05$; ANOVA with Dunnett's post hoc test). The influence of inhibiting ERK phosphorylation (using $5 \mu \mathrm{M}$ U0126) on SFN induced LC3-II expression (c, d) and autophagic vesicles (e, f). Western blots detected products for LC3-I and LC3-II at 18 and $16 \mathrm{kDa}$; phospho and total ERK1/2 were detected at 44/ $42 \mathrm{kDa}$; a band corresponding to $\beta$-actin was detected at $45 \mathrm{kDa}$. Data are presented as mean $\pm \operatorname{SEM}(n=3)$. Asterisk indicates a significant difference from all other groups $(p \leq 0.05$; ANOVA with Tukey's post hoc test)
A

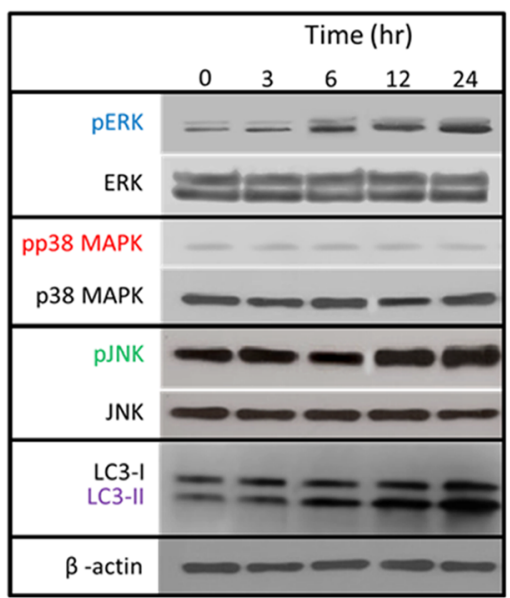

C

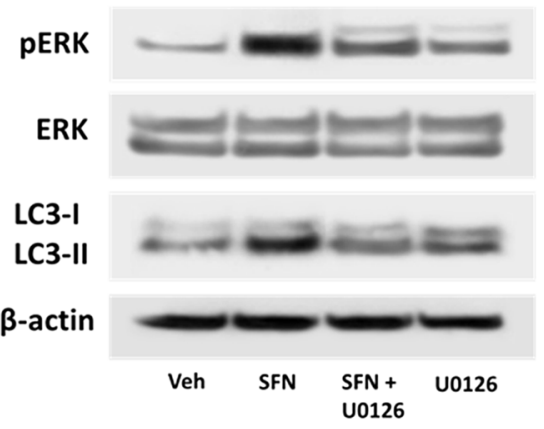

D

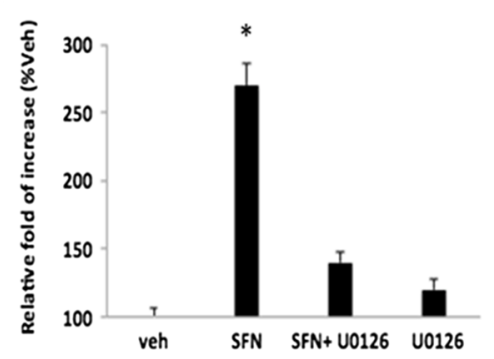

B

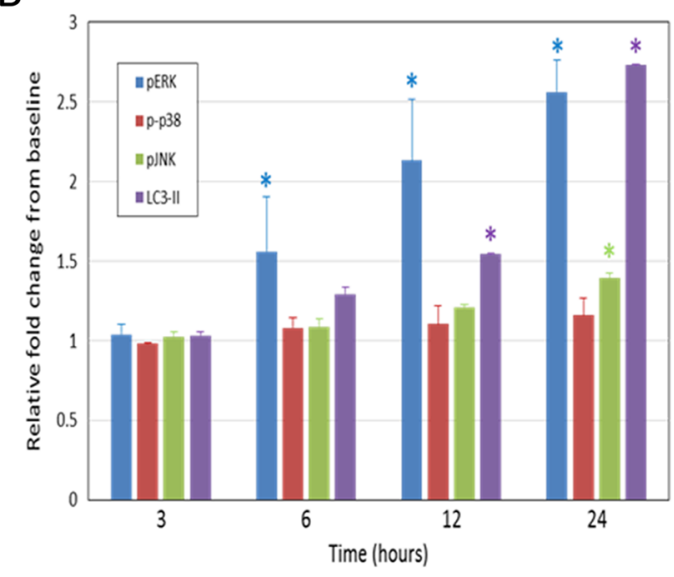

$E$

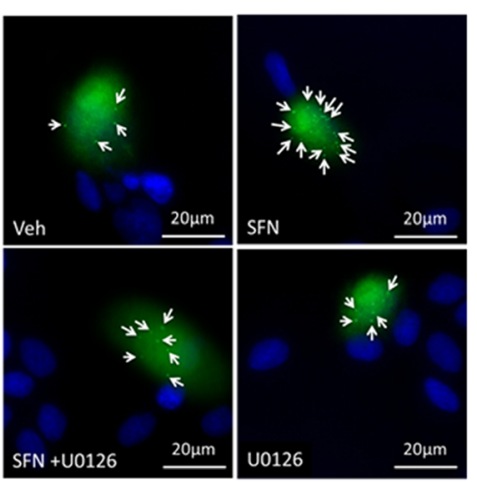

F

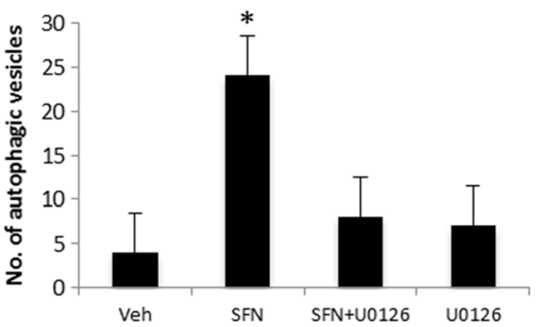

\section{MAPK signaling is critical for SFN-induced autophagy}

The mitogen-activated protein kinases (MAPKs) have been reported to promote autophagy as downstream mediators of ROS [28]. Therefore, we analyzed the level of several phosphorylated MAPKs including p38, c-Jun N-terminal kinase (JNK), and ERK by immunoblotting to examine if MAPKs are involved in SFN-induced autophagy in FHL124 cells. One hundred micromolars SFN did not induce a detectable change in the level of phospho-specific p38 at any time point tested. A significant but relatively weak increase in pJNK level was observed at the 24-h time point. In contrast, levels of phosphorylated ERK1/2 (pERK) in cells treated with SFN $(100 \mu \mathrm{M})$ showed significant increases at 6-, 12-, and 24-h time points (Fig. 5a, b). This increase in ERK activation preceded detectable changes in LC3-II levels (Fig. 5a, b). These results indicate that ERK activation might be involved in
SFN-induced autophagy. We therefore tested this notion by disrupting ERK activation using the MEK inhibitor U0126 (Fig. $5 \mathrm{c}-\mathrm{f}$ ). FHL124 cells were pretreated with U0126 $(5 \mu \mathrm{M})$ for $30 \mathrm{~min}$ before SFN treatment. Application of U0126 significantly reduced SFN-induced increase in LC3II levels and autophagic vesicle incidence. Finally, it has been suggested that SFN-induced activation of ERK is mediated by ROS. We therefore determined whether SFN could induce ROS levels in FHL124 cells. Application of $100 \mu \mathrm{M}$ SFN was found to significantly increase ROS relative to controls (Fig. 6).

\section{Discussion}

The influence of SFN on the physiology of human cells has been studied extensively in recent years, but this work has 


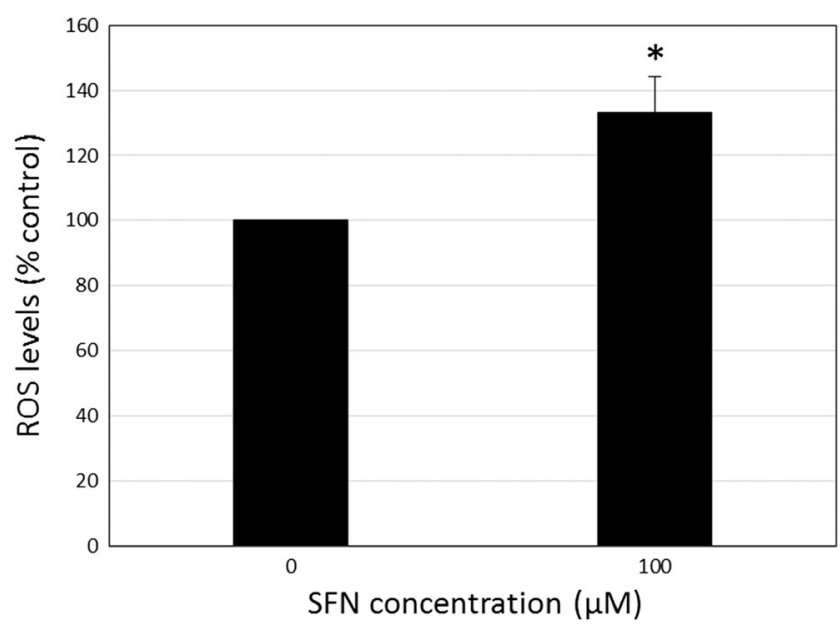

Fig. 6 SFN can increase ROS production in FHL124 human lens epithelial cells. The effect of $100 \mu \mathrm{M}$ SFN on ROS production was detected $2 \mathrm{~h}$ following initial exposure. Data are presented as mean $\pm \operatorname{SEM}(n=4)$. Asterisk indicates a significant difference between treated and nontreated control groups ( $p \leq 0.05$; Student's $t$ test)

largely focused on cancer [16, 32]. However, the functional role of SFN in the prevention of PCO, which affects a large proportion of cataract patients, has not been investigated. In the present study, it was therefore deemed an important opportunity to test the hypothesis that SFN can inhibit the development of PCO. Evaluation of SFN in a human lens capsular bag model supported this notion, and the effective concentrations required mirrored results obtained in a human lens epithelial cell line, FHL124. This therefore suggested that the readily available cell line could be employed to establish mechanisms that underpin SFN-induced effects.

The present study demonstrates that SFN can induce ER stress, which was observed by induction of ER stress gene and protein expression. An important role of the ER is to sense environmental and physiological stresses. This response is mediated by activation and repression of pathways resulting in specific functional outcomes. The ER is the site of protein synthesis, where folding and trafficking are initiated, and also the mediator of internal and external stresses [22]. ER stress can arise because unfolded or misfolded proteins are produced within the ER. Normal levels of unfolded proteins can be counteracted by a number of ER chaperone proteins, but if the level continues to increase, for example, through prolonged oxidative or osmotic stress, then it is detected by the molecule BiP, which in turn activates one or more of three stress pathway initiators (pERK, IRE1, and ATF6). Once a prolonged stress is sensed, then a range of external pathways are initiated and cell death through apoptosis can result [23].

Application of the classical ER stress molecule thapsigargin leads to an inhibition of lens cell growth and, ultimately, to cell death through apoptosis [33, 34]. It has also been reported that diabetic and oxidative stresses to lens cells can give rise to an ER stress response, seen as an increase in
BiP production and caspase activation [35]. Arsenic trioxide $\left(\mathrm{As}_{2} \mathrm{O}_{3}\right)$ is also known to promote ER stress and can reduce lens cell viability [36]. Combinatorial treatment with SFN and $\mathrm{As}_{2} \mathrm{O}_{3}$ or other known ER stressors such as thapsigargin has been employed in the management of different cancers [26, 27] and therefore might provide a promising therapeutic approach for PCO.

It has been suggested that SFN can increase ROS production [20, 28], and in the current study, we confirm that lens cells show elevated ROS levels in response to SFN. Interestingly, as discussed above, SFN exposure in combination with $\mathrm{As}_{2} \mathrm{O}_{3}$ can result in a dramatic increase in levels of ROS compared to treatment with either agent alone [26]. SFN, alone or with $\mathrm{As}_{2} \mathrm{O}_{3}$, decreased intracellular glutathione (GSH) content. Furthermore, addition of the free radical scavenger $N$-acetyl-L-cysteine (NAC) rescued cells from $\mathrm{As}_{2} \mathrm{O}_{3} /$ isothiocyanate-mediated cytotoxicity [26]. $\mathrm{As}^{\mathrm{As}_{2} \mathrm{O}_{3}}$ has been associated with ER stress in the lens and investigated for its potential benefits in the prevention of PCO [36], this suggests that SFN deserves further investigation in combination with $\mathrm{As}_{2} \mathrm{O}_{3}$ in the treatment of $\mathrm{PCO}$ and it will be interesting to establish the role of ROS in SFN-induced ER stress.

Autophagy is a highly controlled process that can be affected by several conditions such as metabolic stress, ER stress, oxidative stress, and hypoxia [37]. The process of autophagy involves the formation of double-membraned vesicles (autophagosomes), which encapsulate the cytoplasm and organelles and fuse with lysosomes, leading to degradation of the contents of the vesicle. It has been associated with specific pathologies including cancer, liver disease, and neurodegeneration by a growing number of studies [38]. Brennan et al. [39] established that autophagy occurs in normal human lens cells, with 42 autophagy genes expressed and a number of autophagosomal proteins detected in both the lens epithelium and fibers. The housekeeping role of autophagy may be particularly important in normal lens maintenance, homeostasis, and fiber differentiation [40, 41]. The loss of lens-specific autophagy-related 5 (Atg5) has been reported to result in age-related cataract formation, and Pik3c3/Vps34 genes are shown to leading cortical cataract in lens [42]. In the present study, we clearly show that SFN is capable of promoting autophagy flux, which occurs in association with reduced viability and increased cell death.

With respect to $\mathrm{PCO}$, previous work using in vitro canine lens capsular bags has indicated that cyclosporine A (CsA)induced cell loss is attributed to an autophagy-related mode of cell death rather than classical apoptosis [43]. While autophagy is typically linked to general maintenance of cells, its relationship with cell death is beginning to emerge [29] and further investigation of the links between cell death and autophagy in response to SFN will be of interest in the future.

ERK is a member of the MAPK family that is involved in many aspects of cell biological functions such as proliferation, 
migration, differentiation, and death $[44,45]$. MAPKs such as p38, ERK, and JNK have been found to have downstream effects of ROS in autophagy induction [46, 47]. Here, we showed that SFN can induce ROS and activate ERK, which in turn facilitates autophagy in human lens epithelial cells. It is speculated that SFN generates ROS, which could activate ERK. A link between ROS and ERK activation is recognized, and it is proposed that this event could occur through several putative mechanisms [48]. One possibility is the activation of upstream growth factor receptors, such as EGF receptor, which have been reported to be activated in response to oxidative stress [49]. EGFR is expressed in both FHL124 cells and the native lens. It is also possible that ROS could alter protein structure of signaling molecules and in doing so promote signaling activity [48]. It is also feasible that MAPK phosphatases, the negative regulators of MAPK signaling, are deactivated and degraded by ROS [48]. Removal of this negative regulator would therefore enable persistent activation of ERK to take place and may best explain the results observed. Signaling mediated through ERK is often associated with growth and survival, but it is also linked to death pathways [45]. It has been suggested that ERK activity can play a role in mediating extrinsic and intrinsic apoptotic pathways. In the case of SFN treatment, sustained ERK activity is likely to facilitate promotion of the intrinsic apoptotic pathway that is associated with release of pro-apoptotic factors from the mitochondrion that will lead to caspase-9 activation, which will then activate caspase $3 / 7$ [45]. The role of ERK in autophagy is also very interesting. Autophagy itself serves an important role in cell maintenance but in some cases can itself lead to cell death $[29,45]$. The mode of cell death could be through conventional apoptosis, but it is also often reported that a distinct autophagy-induced cell death can arise that not only has some features common with conventional apoptosis but also presents distinct morphological changes leading to death. It will be of great interest to tease out the relationship between ROS, ERK, and cell death using free radical scavengers and MEK inhibitors to achieve this.

Considering the data as a whole, it is possible to speculate on the sequence of events that may take place following SFN application that ultimately lead to cell death. The primary initiating event is likely to be the generation of free radicals within the cell that will result in an oxidative stress that triggers an ER stress response and promote ERK activity. These two events are both known to stimulate autophagy, and, thus, increased breakdown of cellular material will result. ER stress is associated with reduced protein synthesis, and, thus, a restricted capacity to replace damaged organelles will compromise the cells and trigger death pathways. Sustained ERK activity is likely to deplete mitochondrial numbers, which will in turn activate caspase-mediated cell death. Similarly, a sustained ER stress could also promote caspase-mediated cell death pathways.
In summary, we have shown that SFN can reduce lens cell viability in both a human lens cell line and a tissue culture model, which has implications for the treatment of PCO. Moreover, we have demonstrated for the first time that SFN can promote ER stress and autophagy in lens cell. SFNinduced autophagy requires MAPK signaling, and we speculate that both ER stress and autophagy are regulated by ROS production.

Acknowledgements We would like to thank all members of the Eye Research Group at the University of East Anglia and Prof. Jenny Gill (UEA) for advice relating to statistical analysis. We also wish to thank Prof. Xiuhua Wan for advice and support. We would also like to express our gratitude to the staff of the East Anglian Eye Bank and Beijing Tongren Eye Bank. We greatly appreciate funding support from the Humane Research Trust (UK), the Beijing New Star of Science and Technology Fund (H020821380190), the Fund of Work Committee for Women and Children of China State Department (2014108), the National Natural Science Fund Projects of China (30471861), and the Beijing Scholars of Beijing Municipal Government.

Compliance with ethical standards Human donor lenses were obtained with informed consent and used in accordance with the tenets of the Declaration of Helsinki. Approval for the study and experimental protocols $(04 / \mathrm{Q} 0102 / 57)$ was granted by a national research ethics committee under the Health Research Authority (UK).

Conflict of interest The authors declare that they have no conflict of interest.

Financial support The Humane Research Trust (UK), the Beijing New Star of Science and Technology Fund (H020821380190), the Fund of Work Committee for Women and Children of China State Department (2014108), the National Natural Science Fund Projects of China (30471861), and the Beijing Scholars of Beijing Municipal Government

Open Access This article is distributed under the terms of the Creative Commons Attribution 4.0 International License (http:// creativecommons.org/licenses/by/4.0/), which permits unrestricted use, distribution, and reproduction in any medium, provided you give appropriate credit to the original author(s) and the source, provide a link to the Creative Commons license, and indicate if changes were made.

\section{References}

1. Wormstone IM, Eldred JA (2016) Experimental models for posterior capsule opacification research. Exp Eye Res 142:2-12

2. Wormstone IM, Wang L, Liu CS (2009) Posterior capsule opacification. Exp Eye Res 88(2):257-269

3. Brown GC, Brown MM, Menezes A, Busbee BG, Lieske HB, Lieske PA (2013) Cataract surgery cost utility revisited in 2012: a new economic paradigm. Ophthalmology 120:2367-2376

4. Smith AF, Klotz A, Wormstone IM (2016) Improving the drug development process by reducing the impact of adverse events: the case of cataracts considered. Drug Discov Today 21(3):510-516

5. Schaumberg DA, Dana MR, Christen WG, Glynn RJ (1998) A systematic overview of the incidence of posterior capsule opacification. Ophthalmology 105:1213-1221 
6. Apple DJ, Solomon KD, Tetz MR, Assia EI, Holland EY, Legler UF, Tsai JC, Castaneda VE, Hoggatt JP, Kostick AM (1992) Posterior capsule opacification. Surv Ophthalmol 37:73-116

7. Mootha VV, Tesser R, Qualls C (2004) Incidence of and risk factors for residual posterior capsule opacification after cataract surgery. $\mathrm{J}$ Cataract Refract Surg 30:2354-2358

8. Wormstone IM (2002) Posterior capsule opacification: a cell biological perspective. Exp Eye Res 74:337-347

9. Kohnen T, Baumeister M, Kook D, Klaproth OK, Ohrloff C (2009) Cataract surgery with implantation of an artificial lens. Dtsch Arztebl Int 106:695-U611

10. Nishi O, Nishi K, Menapace R, Akura J (2001) Capsular bending ring to prevent posterior capsule opacification: 2 year follow-up. J Cataract Refract Surg 27:1359-1365

11. Eldred JA, Spalton D, Wormstone IM (2014) An in vitro evaluation of the Anew Zephyr(R) open bag IOL in the prevention of posterior capsule opacification using a human capsular bag model. Invest Ophth Vis Sci 55:7057-7064

12. Eldred JA, McDonald M, Wilkes HS, Spalton DJ, Wormstone IM (2016) Growth factor restriction impedes progression of wound healing following cataract surgery: identification of VEGF as a putative therapeutic target. Sci Rep 6:24453

13. Wormstone IM, Del Rio-Tsonis K, McMahon G, Tamiya S, Davies PD, Marcantonio JM, Duncan G (2001) FGF: an autocrine regulator of human lens cell growth independent of added stimuli. Invest Ophth Vis Sci 42:1305-1311

14. Wormstone IM, Tamiya S, Anderson I, Duncan G (2002) TGF-beta2-induced matrix modification and cell transdifferentiation in the human lens capsular bag. Invest Ophth Vis Sci 43:2301-2308

15. Duncan G, Wang L, Neilson GJ, Wormstone IM (2007) Lens cell survival after exposure to stress in the closed capsular bag. Invest Ophth Vis Sci 48:2701-2707

16. Juge N, Mithen RF, Traka M (2007) Molecular basis for chemoprevention by sulforaphane: a comprehensive review. Cell Mol Life Sci 64:1105-1127

17. Liu H, Smith AJ, Lott MC, Bao Y, Bowater RP, Reddan JR, Wormstone IM (2013) Sulforaphane can protect lens cells against oxidative stress: implications for cataract prevention. Invest Ophth Vis Sci 54:5236-5248

18. Matsui TA, Murata H, Sakabe T, Sowa Y, Horie N, Nakanishi R, Sakai T, Kubo T (2007) Sulforaphane induces cell cycle arrest and apoptosis in murine osteosarcoma cells in vitro and inhibits tumor growth in vivo. Oncol Rep 18:1263-1268

19. Cheung KL, Kong AN (2010) Molecular targets of dietary phenethyl isothiocyanate and sulforaphane for cancer chemoprevention. AAPS J 12:87-97

20. Xiao D, Powolny AA, Antosiewicz J, Hahm ER, Bommareddy A, Zeng Y, Desai D, Amin S, HermanAntosiewicz A, Singh SV (2009) Cellular responses to cancer chemopreventive agent D,L-sulforaphane in human prostate cancer cells are initiated by mitochondrial reactive oxygen species. Pharmaceut Res 26:1729-1738

21. Lee YJ, Lee SH (2011) Sulforaphane induces antioxidative and antiproliferative responses by generating reactive oxygen species in human bronchial epithelial BEAS-2B cells. J Korean Med Sci 26:1474-1482

22. Boyce M, Yuan J (2006) Cellular response to endoplasmic reticulum stress: a matter of life or death. Cell Death Differ 13:363-373

23. Hetz C (2012) The unfolded protein response: controlling cell fate decisions under ER stress and beyond. Nat Rev Mol Cell Bio 13:89-102

24. Kaur J, Debnath J (2015) Autophagy at the crossroads of catabolism and anabolism. Nat Rev Mol Cell Bio 16(8):461-472
25. Frost LS, Mitchell CH, Boesze-Battaglia K (2014) Autophagy in the eye: implications for ocular cell health. Exp Eye Res 124:56-66

26. Doudican NA, Bowling B, Orlow SJ (2010) Enhancement of arsenic trioxide cytotoxicity by dietary isothiocyanates in human leukemic cells via a reactive oxygen species-dependent mechanism. Leukemia Res 34:229-234

27. Doudican NA, Wen SY, Mazumder A, Orlow SJ (2012) Sulforaphane synergistically enhances the cytotoxicity of arsenic trioxide in multiple myeloma cells via stress-mediated pathways. Oncol Rep 28:1851-1858

28. Jo C, Kim S, Cho SJ, Choi KJ, Yun SM, Koh YH, Johnson GV, Park SI (2014) Sulforaphane induces autophagy through ERK activation in neuronal cells. FEBS Lett 588:3081-3088

29. Marino G, Niso-Santano M, Baehrecke EH, Kroemer G (2014) Self-consumption: the interplay of autophagy and apoptosis. Nat Rev Mol Cell Bio 15:81-94

30. Liu CS, Wormstone IM, Duncan G, Marcantonio JM, Webb SF, Davies PD (1996) A study of human lens cell growth in vitro. A model for posterior capsule opacification. Invest Ophth Vis Sci 37: 906-914

31. Wormstone IM, Tamiya S, Eldred JA, Lazaridis K, Chantry A, Reddan JR, Anderson I, Duncan G (2004) Characterisation of TGF-beta2 signalling and function in a human lens cell line. Exp Eye Res 78:705-714

32. Jackson SJ, Singletary KW (2004) Sulforaphane inhibits human MCF-7 mammary cancer cell mitotic progression and tubulin polymerization. J Nutr 134:2229-2236

33. Duncan G, Wormstone IM, Liu CS, Marcantonio JM, Davies PD (1997) Thapsigargin-coated intraocular lenses inhibit human lens cell growth. Nat Med 3:1026-1028

34. Wang LX, Wormstone IM, Reddan JR, Duncan G (2005) Growth factor receptor signalling in human lens cells: role of the calcium store. Exp Eye Res 80:885-895

35. Mulhern ML, Madson CJ, Danford A, Ikesugi K, Kador PF, Shinohara T (2006) The unfolded protein response in lens epithelial cells from galactosemic rat lenses. Invest Ophth Vis Sci 47:3951-3959

36. Zhang H, Duncan G, Wang L, Liu P, Cui H, Reddan JR, Yang BF, Wormstone IM (2007) Arsenic trioxide initiates ER stress responses, perturbs calcium signalling and promotes apoptosis in human lens epithelial cells. Exp Eye Res 85:825-835

37. Huang J, Lam GY, Brumell JH (2011) Autophagy signaling through reactive oxygen species. Antioxid Redox Sign 14:22152231

38. Choi AM, Ryter SW, Levine B (2013) Autophagy in human health and disease. N Engl J Med 368:651-662

39. Brennan LA, Kantorow WL, Chauss D, McGreal R, He S, Mattucci L, Wei J, Riazuddin SA, Cvekl A, Hejtmancik JF, Kantorow M (2012) Spatial expression patterns of autophagy genes in the eye lens and induction of autophagy in lens cells. Mol Vis 18:1773-1786

40. Costello MJ, Brennan LA, Basu S, Chauss D, Mohamed A, Gilliland KO, Johnsen S, Menko AS, Kantorow M (2013) Autophagy and mitophagy participate in ocular lens organelle degradation. Exp Eye Res 116:141-150

41. Basu S, Rajakaruna S, Reyes B, Van Bockstaele E, Menko AS (2014) Suppression of MAPK/JNK-MTORC1 signaling leads to premature loss of organelles and nuclei by autophagy during terminal differentiation of lens fiber cells. Autophagy 10:1193-1211

42. Morishita H, Eguchi S, Kimura H, Sasaki J, Sakamaki Y, Robinson ML, Sasaki T, Mizushima N (2013) Deletion of autophagy-related 5 (Atg5) and Pik3c3 genes in the lens causes cataract independent of programmed organelle degradation. J Biol Chem 288:11436-11447

43. Chandler HL, Gervais KJ, Lutz EA, Curto EM, Matusow RB, Wilkie DA, Gemensky-Metzler AJ (2015) Cyclosporine A prevents 
ex vivo PCO formation through induction of autophagy-mediated cell death. Exp Eye Res 134:63-72

44. Ramos JW (2008) The regulation of extracellular signalregulated kinase (ERK) in mammalian cells. Int J Biochem Cell B 40:2707-2719

45. Cagnol S, Chambard JC (2010) ERK and cell death: mechanisms of ERK-induced cell death - apoptosis, autophagy and senescence. FEBS J 277:2-21

46. Pattingre S, Bauvy C, Codogno P (2003) Amino acids interfere with the ERK1/2-dependent control of macroautophagy by controlling the activation of Raf- 1 in human colon cancer HT-29 cells. J Biol Chem 278:16667-16674
47. Pattingre S, Petiot A, Codogno P (2004) Analyses of Galphainteracting protein and activator of G-protein-signaling-3 functions in macroautophagy. Method Enzymol 390:17-31

48. Son Y, Cheong YK, Kim NH, Chung HT, Kang DG, Pae HO (2011) Mitogen-activated protein kinases and reactive oxygen species: how can ROS activate MAPK pathways? J Signal Transduct 2011:792639

49. Nakashima I, Takeda K, Kawamoto Y, Okuno Y, Kato M, Suzuki H (2005) Redox control of catalytic activities of membrane-associated protein tyrosine kinases. Arch Biochem Biophys 434:3-10 